\title{
Stigmatised attitudes towards intellectual disability: a randomised crossover trial
}

\author{
Sabu John Varughese, ${ }^{1}$ Jason Luty ${ }^{2}$
}

The Psychiatrist (2010), 34, 318-322, doi: 10.1192/pb.bp.109.027789

${ }^{1}$ Community Drug and Alcohol Service, Thurrock; ${ }^{2}$ South Essex Partnership NHS Trust and Cambridge \& Peterborough Mental Health NHS Trust

Correspondence to Jason Luty (jason.luty@yahoo.co.uk)

\begin{abstract}
Aims and method Tackling discrimination, stigma and inequalities in mental health is a major UK government objective yet people with intellectual disabilities continue to suffer serious stigma and discrimination. The project aimed to determine the effect of viewing a picture of a person with intellectual disability on stigmatised attitudes. The 20-point Attitude to Mental IIIness Questionnaire (AMIQ) was used and a representative panel of members of the general public were randomised to complete the questionnaire either with (experimental) or without (control) looking at a picture of a man with Down syndrome. Six months later the same experiment was performed with the groups crossed over.
\end{abstract}

Results Results were received for 360 participants (response rate $87-93 \%$ ). The sequence (control or experimental) had no significant effect on the outcome. The mean AMIQ score in the control groups was 1.56 (s.d. $=2.85$, s.e. $=0.21, n=186$ ) and in the experiment group (after looking at the pictures) was 2.43 (s.d. $=2.59$, s.e. $=0.12$, $n=174$; median difference 1, $P=0.0016$ Mann-Whitney $U$-test; effect size 0.23 ).

Clinical implications Looking at a picture of a man with Down syndrome significantly reduces reported stigmatised attitudes.

Declaration of interest None.
Tackling stigma and inequalities in health is a major UK government objective. ${ }^{1,2}$ Stigma is a social construction that devalues people due to a distinguishing characteristic or mark. ${ }^{3}$ The World Health Organization (WHO) and World Psychiatric Association (WPA) recognise that the stigma attached to mental disorders is strongly associated with suffering, disability and poverty. ${ }^{4}$ Stigma is also a major barrier to treatment-seeking behaviour. ${ }^{5}$ Many studies show that negative attitudes towards the mentally ill are widespread. ${ }^{6}$ Furthermore the media generally depicts mentally ill people as violent, erratic and dangerous. ${ }^{7}$ There have been several attempts to reduce the stigma of mental illness including the UK Royal College of Psychiatrists' Changing Minds campaign, the current See Me campaign in Scotland and the Time to Change campaign in England. ${ }^{6}$

Society's neglect and ill-treatment of people with intellectual disabilities is infamous. ${ }^{8,9}$ Various organisations report that people with intellectual disabilities encounter stigma, prejudice and suffer continued denial of their human rights. ${ }^{10,11}$ However, very little research is published on the stigma of intellectual disability, although excellent recent British research reports described a new instrument for measuring the stigma experienced by people with intellectual disabilities and describes the current situation. ${ }^{12}$ Regardless of this, the proportion of research reports on intellectual disability was consistently less than any other diagnostic category in a survey of five high-impact psychiatric journals. $^{13}$ In a Mencap survey of 5000 people with intellectual disabilities, over $80 \%$ of people had been bullied in the previous year, a third on a weekly basis, half reported verbal abuse and a quarter reported physical assaults. ${ }^{14}$ People with intellectual disabilities were twice as likely to be victims of crime. ${ }^{15}$ Inequalities in healthcare were identified by an investigation conducted by the Disability Rights Commission in the UK and Mencap's (2007) Death by Indifference report. ${ }^{16,10}$ The UK government report, Valuing People, aims to counter these problems and improve the lives of people with intellectual disabilities by ensuring that services respect their rights, choices, independence and social inclusion and ensuring their access to mainstream services. ${ }^{17}$

It is often held that the disfigured or 'dysmorphic' facial appearance may further stigmatise people. ${ }^{18-20}$ By comparison, marketing strategies for commercial products invariably associate their product with positive images and avoid associating it with any negative images. ${ }^{21-27}$ Hence the study aimed to look at the effect of viewing pictures of dysmorphic people with intellectual disabilities on stigmatised attitudes.

\section{Method}

\section{Participants}

Participants were from a panel of 200 people drawn from the UK general population recruited using direct mailshots and advertisements in local newspapers as described in a previous study. ${ }^{28}$ 


\section{Instruments}

The five-item Attitude to Mental Illness Questionnaire (AMIQ) is a brief, self-completion questionnaire. ${ }^{27,29}$ Respondents read a short vignette describing an imaginary person and answered five questions (Appendix). Individual questions were scored on a five-point Likert scale (maximum +2, minimum -2) with blank questions, 'neutral' and 'don't know' scored zero. The total score for each vignette ranged between -10 and +10 . The AMIQ has been shown to have good psychometric properties in a sample of over 800 members of the UK general public (one component accounted for $80.2 \%$ of the variance; test-retest reliability was 0.702 (Pearson's correlation coefficient); alternate test-reliability $v$. Corrigan's attribution questionnaire was 0.704 (Spearman's rank correlation rho); Cronbach's alpha was 0.93). ${ }^{28}$ Further details of the AMIQ are included in the Discussion.

\section{Procedure}

Participants were block randomised using the randomisation function of the Stats Direct Statistical Package (Version 2.4 for Windows Excel, StatsDirect, www.statsdirect.com). The control group were asked to complete the AMIQ with the following description: 'Oliver has Down syndrome. He is 32 years old and lives with his parents. He cannot read or write but he is happy and cheerful and keen to help people'. The experimental group were asked to look at a picture of a young man with the physical appearance of Down syndrome wearing a shirt and tie in an office (the picture was a model from a commercial photo-image gallery, see cover, this issue). Participants were then asked to complete the AMIQ. Six months later the experiment was repeated but all participants were crossed between experimental and control group.

\section{Data analysis}

Randomisation, correlation coefficients and non-parametric (Mann-Whitney) tests were used to generate and compare differences in subgroups using the StatsDirect statistical computer software package (Version 2.4). Arithmetic mean scores are used to summarise the ordinal data (Likert scale scores) for convenience according to common statistical practice, although analysis involves use of the median scores in the Mann-Whitney tests.

\section{Results}

\section{Demographic data}

Overall, $26 \%$ of respondents were male; the mean age was 47.9 years $($ s.e. $=1.5)$; $55 \%$ of participants were in paid employment, $17 \%$ were retired; $92 \%$ described their ethnic group as White British.

Completed questionnaires were received for 360 people (response rate $93 \%$ at baseline; $87 \%$ at 6 -month crossover). The mean AMIQ score in the control groups was 1.56 (s.d. = 2.85 , s.e. $=0.21, n=186$ ). The mean score in the experiment group (after looking at the pictures) was 2.43 (s.d. $=2.59$, s.e. $=0.12, n=174$, median difference $1 ; P=0.0016$ MannWhitney $U$-test, effect size 0.23 ). The order of exposure (control or experimental) had no significant effect on the outcome (there was no significant difference between outcomes when the control groups were compared before and after the crossover, $P=0.87$ ).

\section{Discussion}

\section{Strengths and limitations}

The AMIQ was used in this project as it is convenient and has been well-validated. ${ }^{28-30}$ Other instruments are available, although these tend to be much longer, involve interviews or tend to address the experience of stigma by people with mental illness. ${ }^{28,31}$ The AMIQ was designed as a brief instrument to measure stigmatised attitude in members of the general public. It draws from Corrigan's attribution model of public discrimination that proposes that people have negative attitudes towards the mentally ill because people with a mental illness have responsibility for their illness and are more blameworthy than people with a physical illness. ${ }^{4}$ Other features identified in Corrigan's model that may distinguish between the perception of mental and physical illness include their tendency to illicit emotional responses such as pity, anger, fear, or helping/ rejecting responses. The AMIQ was validated in a postal survey of a sample of 1079 UK adults. The AMIQ is a selfreport questionnaire with five-point Likert scale responses originally validated in response to short fictional vignettes. The AMIQ showed highly stigmatised attitudes to people with addictive disorders but more positive attitudes to those with depression or self-harm. ${ }^{28}$ Results from a smaller follow-up sample showed that attitudes towards people with alcohol dependence and schizophrenia were intermediate. It has good test-retest reliability as well as face and construct validity. The AMIQ was also compared with the 21-item Corrigan's attributions questionnaire that has been validated as a measure of stigmatised attitudes towards people with mental illness. ${ }^{4,28,32}$ Fifty participants received the AMIQ and attributions questionnaire and were asked to complete both in relation to the schizophrenia vignette. The attribution questionnaire was scored from 0 to a maximum of 64 , with a mean score of 38.7 (s.e. $=1.8$ ). Kendall's tau $b=0.563 \quad(P<0.001)$ and Spearman's rank correlation rho $=0.704 \quad(P<0.001)$ indicated good alternative test reliability.

Although there was an excess of female respondents, age and employment status of participants were reasonably matched to that from UK census surveys. Hence the sample appears to be a reasonable cross-section of the British public. However, it is self-selecting and may not generalise across the whole population. Ideally, interviews could be conducted using a quota survey of households with repeat visits for non-responders. ${ }^{6}$ Unfortunately, this is prohibitively expensive.

The crossover trial took place after 6 months - a significant period of time which meant it was unlikely that the effects of the first phase would still be present. Furthermore, there was no significant difference between outcomes when the control groups were compared before and after the crossover. The study presented a hypothetical person with intellectual disability - the picture was a model from a commercial photo-image gallery. The picture was of a 
young man with Down syndrome wearing a suit. It is possible that participants were responding positively towards features other than his dysmorphic facial appearance such as the suit, background or his cheerful expression. Nevertheless, this report does indicate that including a photograph of a dysmorphic person with an intellectual disability can elicit a positive response and, as such, people with intellectual disabilities and their advocates should be aware that promoting a photograph of a dysmorphic person may be advantageous.

The results rely on a hypothetic individual and situation. This is less accurate than real experience - it was not possible to measure stigmatised behaviour towards real people with intellectual disabilities. Moreover, the written views and expressed attitudes may not translate into any enduring behavioural change. Although there was no direct contact between participants and researchers, participants are likely to make some assumptions about the potentially liberal beliefs of researchers. Hence social desirability bias may affect the results. However, the results from other similar studies show a negative view of people with active substance use disorder and suggest that participants had little reservation about indicating their disapproval of these disorders. ${ }^{28,30}$ This is confirmed in other reports. ${ }^{33}$ This would indicate that social desirability bias had only a modest effect. Furthermore, social desirability bias would affect both the experimental and control groups equally.

\section{Main findings}

The impact of visual imagery has been widely accepted in marketing since the 1920s: indeed the expression, 'a picture paints a thousand words' was popularised by Frederick R. Barnard in a marketing journal. ${ }^{34}$ Stigmatised attitudes are widely reported towards people as a result of disfigurement or dysmorphic facial appearance. ${ }^{18-20,32}$ Hence the researchers, wrongly, assumed that the picture of a man with Down syndrome would produce a more negative stigmatised attitude than simply asking participants to complete the scoring instrument without viewing any pictures. In fact, looking at a picture of the young man with Down syndrome actually reduced stigmatised attitudes by a small but statistically significant extent. These results are in contrast to most marketing strategies that invariably recommend associating a product with a successful, physically attractive individual. ${ }^{21-27}$ Hence looking at pictures of an individual may actually personalise the description and evoke a more sympathetic outcome than simply asking participants to rate a hypothetical person based purely on a written description.

Although the difference was small (effect size 0.23), it was highly statistically significant. Wolff and colleagues ${ }^{35}$ reported a labour-intensive controlled study of the effect of a public education campaign on community attitudes towards people with mental illness. It produced effects sizes of 1.23 for fear and exclusion, 1.22 for social control and 0.66 for goodwill. The scores for both groups were less than 3 on the AMIQ scale (range -10 to +10 ). This is significantly less than the scores reported for someone with diabetes or a practising Christian both of whom consistently score above $5{ }^{28}$ However, the score of 2.43 was almost identical to that previously reported towards a fictitious individual who had taken an overdose while depressed (2.35). Presenting a picture and a description of a man with an intellectual disability was the least stigmatising presentation of mental illness so far reported using the AMIQ. Hence, although there is likely to be a significant degree of stigma associated with intellectual disability, presenting members of the public with pictures of people with intellectual disabilities significantly reduced stigmatised attitudes.

\section{Methods to reduce the stigma of mental illness}

The Royal College of Psychiatrists' Changing Minds campaign aimed to promote positive images of mental illness, challenge misrepresentations and discrimination and educate the public to the real nature and treatability of mental disorder. ${ }^{6}$ Crisp et al's large survey showed that people with substance use disorders were the most stigmatised of all those with mental disorder. ${ }^{33}$ More recently, national anti-stigma campaigns have been launched in Scotland and England (e.g. www.seemescotland. org.uk/ and www.time-to-change.org.uk). Unfortunately, there have been recent reports that national anti-stigma campaigns are not particularly effective. ${ }^{13,36,37}$ These reports discuss the disappointing results to date from the Defeat Depression campaign, the Changing Minds campaign and the Scottish See Me campaign. The English Time to Change campaign is sponsored by the National Lottery and mental health charities including MIND and Rethink. Although a significant amount of work has been carried out on the stigmatising effect of a diagnosis of schizophrenia, very little research has been done on stigmatised attitudes directed against people with intellectual disability. ${ }^{8,13,14,38}$ For example, the stigma of intellectual disability is not addressed by either the Changing Minds or Time to Change campaigns or the UK government publication Action on Mental Health. ${ }^{1}$ Methods of dealing with stigma are not addressed in the UK Department of Health report, Valuing People, which specifically concerns people with intellectual disability. ${ }^{17}$

Action on Mental Health - A Guide to Promoting Social Inclusion provides 12 individual factsheets to reduce stigma. ${ }^{1}$ This supplements the efforts of the Changing Minds campaign. Both give practical advice to health agencies, employers and stakeholders to tackle stigma. Providing factual information in brief factsheets ${ }^{39,40}$ or through extensive interventions, such as educational courses, has been reported to reduce stigma. ${ }^{32,41,42}$ Unfortunately, responses tend to be small, especially if the negative consequences of mental illness are also disseminated. Knox et al showed that addressing stigmatised attitudes to mental illness among 4 million members of the US armed forces with mandatory training to recognise and treat mental illness significantly reduced suicide rates but not stigmatised attitudes. ${ }^{43}$ Pinfold et al reported a project in which 472 English secondary school children attended mental health awareness workshops. ${ }^{44}$ Overall, there was a small but positive shift in their understanding of mental illness. However, it was possible in both these settings to insist that participants engaged in the anti-stigma training, whereas involvement of the general public is entirely voluntary. 
Penn et al reported a study of 163 US undergraduates who were assigned randomly to four groups: three watched a documentary - about schizophrenia (represented realistically), polar bears or being overweight - and the fourth was a 'no video' control group. ${ }^{45}$ The schizophrenia documentary did not change attitudes. Depicting the negative consequences of schizophrenia may be realistic but may not be the best way to reduce stigma. Depicting a success story may be more effective, although viewers may then classify this as an exception to the rule. ${ }^{32}$ By contrast, a study showed that presenting recovered patients in a positive manner can significantly reduce the stigma of alcoholism, although the effects on schizophrenia were negligible. $^{30}$ Luty et al also used a brief face-to-face intervention (motivational interviewing) to reduce the stigma of alcoholism, although the effect was modest. ${ }^{31}$

Promoting direct interpersonal contact with people who are mentally ill may be an effective strategy, but the amount of contact required remains unknown. ${ }^{32,35,39,44}$ It would be difficult, in practice, to ensure that a significant proportion of the public had contact with people with a severe mental illness. Our report indicates that looking at a picture of a dysmorphic man does reduce stigmatised attitudes significantly and this may act as an effective substitute for direct contact.

\section{Appendix}

\section{Attitudes to Mental IIIness Questionnaire (AMIQ) ${ }^{28,29}$}

This is a fictitious report: 'Oliver has Down syndrome. He is 32 years old and lives with his parents. He cannot read or write but he is happy and cheerful and keen to help people.'

1 Do you think that this would damage Oliver's career? Strongly agree ${ }^{-2} /$ Agree $^{-1} /$ Neutral $^{0} /$ Disagree $^{+1} /$ Strongly disagree $^{+2} /$ Don't know $^{0}$

2 I would be comfortable if Oliver was my colleague at work?

Strongly agree ${ }^{+2} /$ Agree $^{+1} /$ Neutral $^{0} /$ Disagree $^{-1} /$ Strongly disagree $^{-2}$ /Don't know ${ }^{0}$

3 I would be comfortable about inviting Oliver to a dinner party?

Strongly agree ${ }^{+2} /$ Agree $^{+1} /$ Neutral $^{0} /$ Disagree $^{-1} /$ Strongly disagree ${ }^{-2} /$ Don't know $^{0}$

4 How likely do you think it would be for Oliver's wife to leave him?

Very likely ${ }^{-2} /$ Quite likely $^{-1} / \mathrm{Neutral}^{\mathrm{O}} / \mathrm{Unlikely}^{+1} /$ Very unlikely $^{+2} /$ Don't know $^{0}$

5 How likely do you think it would be for Oliver to get in trouble with the law?

Very likely ${ }^{-2} /$ Quite likely ${ }^{-1} /$ Neutral $^{0} /$ Unlikely $^{+1} /$ Very unlikely $^{+2} /$ Don't know $^{0}$

\section{About the authors}

Sabu John Varughese is a Staff Grade Psychiatrist (Specialty Doctor) at the Community Drug and Alcohol Service, Thurrock. Jason Luty is a Consultant in Addictions Psychiatry at the South Essex Partnership NHS Trust and also an Honorary Consultant in Addictions Psychiatry at the Cambridge \& Peterborough Mental Health NHS Trust.

\section{References}

1 Office of the Deputy Prime Minister. Action on Mental Health - A Guide to Promoting Social Inclusion. Office of the Deputy Prime Minister, 2004 (http://www.cabinet office.gov.uk/media/cabinet office/ social_exclusion_task_force/assets/publications_1997_to_2006/ action_on_mh.pdf).

2 Darzi A. Our NHS, Our Future. NHS Next Stage Review: Interim Report. Department of Health, 2007.

3 Biernat M, Dovidio JF. Stigma and stereotypes. In The Social Psychology of Stigma (eds TF Heatherton, RE Kleck, MR Hebl): 88-125. Guilford Press, 2000.

4 Corrigan P, Markowitz FE, Watson A, Rowan D, Kubiak MA. An attribution model of public discrimination towards people with mental illness. J Health Soc Behav 2003; 44: 162-79.

5 Appleby L. Safer Services. Department of Health, 1999.

6 Crisp AH, Gelder MG, Rix G, Meltzer HI, Rowlands OJ. Stigmatisation of people with mental illnesses. Br J Psychiatry 2000; 177: 4-7.

7 Granello D, Pauley PS, Carmichael A. Relationship of the media to attitudes towards people with mental illness. J Couns, Educ Dev 1999; 38: 89-110.

8 Sperlinger A. Introduction. In Adults with Learning Disabilities: A Practical Approach for Health Professionals (eds J O'Hara, A Sperlinger). John Wiley \& Sons, 1997.

9 O'Hara J. Learning disabilities and ethnicity: achieving cultural competence. Adv Psychiatr Treat 2003; 9: 166-74.

10 Mencap. Death by Indifference. Mencap, 2007 (http://www.mencap. org.uk/case.asp?id=52).

11 European Union Monitoring and Advocacy Programme. Report on People with Intellectual Disabilities. Open Society Institute, 2004 (http:// www.eumap.org/)

12 Ali A, Strydom A, Hassiotis A, Williams R, King M. A measure of perceived stigma in people with intellectual disability. $\mathrm{Br} J$ Psychiatry 2008; 193: 410-5

13 Luty J, Umoh O, Sessay M, Sarkhel A. Effectiveness of Changing Minds campaign factsheets in reducing stigmatised attitudes towards mental illness. Psychiatr Bull 2007; 31: 377-81.

14 Mencap. The Need to Combat Bullying of People with a Learning Disability. Mencap, 2000.

15 Mencap. Barriers to Justice. Mencap, 1997.

16 Disability Rights Commission. Equal Treatment: Closing the Gap. A Formal Investigation into the Physical Health Inequalities Experienced by People with Learning Disabilities and/or Mental Health Problems. Disability Rights Commission, 2006 (http://www. library.nhs.uk/ MENTALHEALTH/ViewResource.aspx?resID=187303).

17 Department of Health. Valuing People: A New Strategy for People with Learning Disability for the 21st Century. Department of Health, 2001 (http://www.archive.official-documents.co.uk).

18 Houston V, Bull R. Do people avoid sitting next to someone who is facially disfigured? Eur J Soc Psychol 1994; 24: 279-84.

19 Strauss RP, Ramsey BL, Edwards TC, Topolski TD, Kapp-Simon KA Thomas CR, et al. Stigma experiences in youth with facial differences: a multi-site study of adolescents and their mothers. Orthod Craniofac Res 2007: 10: 96-103.

20 Kaney S. Overcoming the stigma of disfigurement. In Stigma and Social Exclusion in Healthcare (eds T Mason, C Carlisle, C Watkins E Whitehead): 142. Routledge, 2001.

21 Atkinson RL, Atkinson RC, Smith EE, Bem DJ, Nolen-Hoeksema S. Hilgard's Introduction to Psychology (12th edn). Harcourt Brace, 1996.

22 McGrouther DA. Facial disfigurement. The last bastion of discrimination. BMJ 1997; 314: 991

23 Till BD, Busler M. Matching products with endorsers: attractiveness versus expertise. J Consum Market 1998; 15: 576-86.

24 Wilmshurst J, Mackay A. The Fundamentals and Practice of Marketing (4th edn). Butterworth, 2002. 
25 Kahle LR, Kim C. Creating Images and the Psychology of Marketing Communication: 163. Psychology Press, 2006.

26 Patzer GL The Power and Paradox of Physical Attractiveness. Universal Publishers, 2007

27 Lin CL, Yeh JT. Comparing society's awareness of women: mediaportrayed idealized images and physical attractiveness. J Business Ethics 2009; 90: 61-79.

28 Luty J, Fakuda D, Umoh O, Gallagher J. Validation of a short instrument to measure stigmatised attitudes towards mental illness. Psychiatr Bull 2006; 30: 257-60.

29 Cunningham JA, Sobell LC, Chow VMC. What's in a label? The effects of substance types and labels on treatment considerations and stigma. J Stud Alcohol 1993; 54: 693-9.

30 Luty J, Rao H, Arokiadass SMR, Easow JM, Sarkhel A. The repentant sinner: methods to reduce stigmatised attitudes towards mental illness. Psychiatr Bull 2008; 32: 327-32.

31 Luty J, Umoh O, Nuamah F. The effect of brief motivational interviewing on stigmatised attitudes towards mental illness. Psychiatr Bull 2009; 33: $212-4$

32 Corrigan PW, Penn DL. Lessons from social psychology on discrediting psychiatric stigma. Am Psychol 1999; 54: 765-76.

33 Crisp AH, Gelder M, Goddard E, Meltzer H. Stigmatization of people with mental illness: a follow-up study within the Changing Minds campaign of the Royal College of Psychiatrists. World Psychiatry 2005; 4: $106-34$

34 Barnard FR. One look is worth a thousand words. Printer's Ink 1921; December (http://www.phrases.org.uk/meanings/a-picture-is-worth-athousand-words.html).
35 Wolff G, Pathare S, Craig T, Leff J. Public education for community care. A new approach. Br J Psychiatry 1996; 168: 441-7.

36 Paykel ES, Hart D, Priest RG. Changes in public attitudes to depression during the Defeat Depression Campaign. Br J Psychiatry 1998; 173: 51922.

37 Mehta N, Kassam A, Leese M, Butler G, Thornicroft G. Public attitudes towards people with mental illness in England and Scotland, 19942003. Br J Psychiatry 2009; 194: 278-84.

38 Penn DL, Kommana S, Mansfield M, Link BG. Dispelling the stigma of schizophrenia. Schizophr Bull 1999; 25: 437-46.

39 Penn DL, Guynan K, Daily T, Spaulding WD, Garbin P, Sullivan M. Dispelling the stigma of schizophrenia. Schizophr Bull 1994; 20: 567-77.

40 Thornton JA, Wahl OF. Impact of newspaper articles on attitudes towards mental illness. J Commun Psychol 1996; 24: 17-25.

41 Mayville E, Penn DL. Changing societal attitudes towards persons with severe mental illness. Cogn Behav Pract 1998; 5: 241-53.

42 Penn DL, Martin J. The stigma of severe mental illness. Some potential solutions for a recalcitrant problem. Psychiatr Q 1998; 69: 235-47.

$43 \mathrm{Knox} T$, Smith J, Hereby $\mathrm{H}$. Risk of suicide and related adverse outcomes after exposure to a suicide prevention programme in the US air force: cohort study. BMJ 2003; 327: 1376-8.

44 Pinfold V, Toulmin H, Thornicroft G, Huxley P, Farmer P, Graham T. Reducing psychiatric stigma and discrimination: evaluation of educational interventions in UK secondary schools. $\mathrm{Br} J$ Psychiatry 2003; 182: 342-6

45 Penn DL, Chamberlin C, Mueser KT. The effects of a documentary film about schizophrenia on psychiatric stigma. Schizophr Bull 2003; 29: 383-91.

\section{Use of the HoNOS-LD in identifying domains of change}

Bradley Hillier, ${ }^{1}$ Lucy Wright, ${ }^{2}$ Andre Strydom, ${ }^{3}$ Angela Hassiotis ${ }^{3}$

The Psychiatrist (2010), 34, 322-326, doi: 10.1192/pb.bp.108.024323

${ }^{1}$ Islington Learning Disabilities Partnership, London; ${ }^{2}$ Camden Learning Disabilities Service; ${ }^{3}$ Camden and Islington NHS Foundation Trust \& University College London

Correspondence to Angela Hassiotis (a.hassiotis@ucl.ac.uk)
Aims and method To analyse clinical outcome indicator data from the Health of the Nation Outcome Scales for People with Learning Disabilities (HoNOS-LD) in adults with intellectual disability admitted to mental health wards during a 19-month period; and to identify clinically relevant domains of change associated with in-patient admission.

Results Significant improvements were found in mental state, behaviour and social functioning. Improvements were also found in cognition and activities of daily living.

Clinical implications The HoNOS-LD is a useful tool for measuring clinical outcomes in several relevant domains and guiding in-patient treatment in learning disability psychiatry. It may also provide a currency for payment-by-results and influence the commissioning of learning disability services.

Declaration of interest None.
Over the past 25 years there has been a significant change in the provision of services for people with intellectual disabilities. Large institutions have either closed or become much smaller in the UK, USA and other countries. ${ }^{1}$ Many people with intellectual disabilities and mental health needs and/or challenging behaviour now live in their family home or in a variety of supported living options and psychiatric services are increasingly provided in the community. However, the most recent White Paper in England for people with intellectual disabilities ${ }^{2}$ continues to recognise that at times an in-patient admission for the purposes of assessment and treatment may be necessary 